$\mid$ Pbilosophia $\quad$ Philosophia Scientiæ

Scientie Travaux d'histoire et de philosophie des sciences

$17-2 \mid 2013$

The Mind-Brain Problem in Cognitive Neuroscience

\title{
Memory and Consciousness
}

\section{Paula Droege}

\section{(2) OpenEdition}

\section{Journals}

Electronic version

URL: http://journals.openedition.org/philosophiascientiae/865

DOI: 10.4000/philosophiascientiae.865

ISSN: $1775-4283$

\section{Publisher}

Éditions Kimé

\section{Printed version}

Date of publication: 1 May 2013

Number of pages: 171-193

ISBN: 978-2-84174-631-6

ISSN: $1281-2463$

\section{Electronic reference}

Paula Droege, « Memory and Consciousness », Philosophia Scientiæ [Online], 17-2 | 2013, Online since 27 June 2013, connection on 02 November 2020. URL : http://journals.openedition.org/ philosophiascientiae/865; DOI : https://doi.org/10.4000/philosophiascientiae.865 


\title{
Memory and Consciousness
}

\author{
Paula Droege \\ Pennsylvania State University (USA)
}

Résumé : Les théories philosophiques de la mémoire font rarement la distinction entre différents types de mémoire : procédurale, sémantique et épisodique. Je soutiens une théorie de la représentation temporelle pour expliquer la caractéristique unique de la mémoire épisodique comme étant la seule forme de mémoire consciente. Une distinction précise entre représentation implicite et explicite montre comment le passé figure dans la mémoire. Dans la mémoire procédurale et sémantique, l'influence du passé est implicite, j'entends par là que l'expérience passée est utilisée mais pas représentée dans les compétences ou la connaissance. La mémoire épisodique, à l'inverse, dépend de la représentation d'une expérience passée comme passée. Dans le cadre d'une théorie de la représentation temporelle de la conscience, un état conscient représente le moment présent ; et dans le cas d'une mémoire épisodique, cela inclut une représentation de l'expérience passée. L'explication intégrée de la «sensation de passéité » comprend l'expérience passée comme une partie du contenu explicite de l'état conscient. Un souvenir épisodique est une représentation du présent qui inclut une représentation du passé. Tandis qu'une théorie de la conscience d'ordre supérieur peut ne pas donner de raison expliquant pourquoi seuls les souvenirs épisodiques sont conscients, une théorie temporelle explique pourquoi les souvenirs épisodiques sont à la fois d'ordre supérieur et conscients. Enfin, je prends en compte le rôle essentiel de la mémoire épisodique dans la formation d'un soi temporellement étendu. Les exigences d'un environnement social poussent au développement d'une capacité à suivre les états mentaux des autres et de soi au fil du temps. En intégrant l'expérience passée (et future) dans le présent, la mémoire épisodique prolonge l'expérience dans le temps pour qu'un sens de soi prenne forme. À travers un examen minutieux de la fonction de représentation temporelle, nous pouvons comprendre pourquoi le passé n'est pas représenté de manière consciente dans la mémoire procédurale et sémantique, et la valeur d'une représentation consciente du passé dans la mémoire épisodique.

Abstract: Philosophical theories of memory rarely distinguish between importantly different sorts of memory: procedural, semantic and episodic. I 
argue for a temporal representation theory to explain the unique characteristic of episodic memory as the only form of conscious memory. A careful distinction between implicit and explicit representation shows how the past figures in memory. In procedural and semantic memory, the influence of the past is implicit by which I mean that the past experience is used but not represented in the skill or knowledge. Episodic memory, in contrast, depends on representing a past experience as past. On a temporal representation theory of consciousness, a conscious state represents the present moment, and in the case of episodic memory, it includes a representation of past experience. The embedded account of the 'feeling of pastness' takes past experience to be part of the explicit content of a conscious state. An episodic memory is a representation of the present that includes a representation of the past. Whereas a higher-order theory of consciousness can give no reason why only episodic memories are conscious, a temporal theory explains why episodic memories are both higher-order and conscious. Finally, I consider the essential role of episodic memory in the formation of a temporally extended self. The demands of a social environment motivate development of an ability to track the mental states of others and oneself over time. By incorporating past experience (and future experience) into the present, episodic memory extends experience in time to form the sense of self. Through a careful examination of the function of temporal representation, we can see why the past is not consciously represented in procedural and semantic memory and the value of consciously representing the past in episodic memory.

The phenomenologists were right about one thing. An investigation into the features of the conscious mind should begin with the consideration of how the mind appears to its bearer. So here are some ways my memories appear to me (or in the last case, to a famous author):

Though I haven't ridden a skateboard in years, I remember how to ride one. Despite a somewhat wobbly start and a far poorer sense of balance, I am able to push off, glide, turn and stop- this last rather less than gracefully.

In the course of a long car trip to the Midwest I found myself spontaneously reciting all the ingredients in a McDonald's Big Mac sandwich.

And once I had recognised the taste of the crumb of madeleine soaked in her decoction of lime-flowers which my aunt used to give me [...] immediately the old grey house upon the street where her room was, rose up like the scenery of a theatre to attach itself to the little pavilion, opening on to the garden, which had been built out behind it for my parents [...]; and with the house the town, from morning to night and in all weathers, the Square where I was sent before luncheon, the streets along which I used to run 
errands, the country roads we took when it was fine. [Proust 1928, $65-66]$

What can we say about these different forms of memory and their relation to consciousness? Drawing on the psychological literature about memory, we can identify the three types of memory described above as procedural, semantic and episodic. In all three cases, past experiences influence present action in some way, even as the form of influence differs. Before I develop the differences in these cases, a brief note on terminology: While 'experience' is often used interchangeably with 'consciousness', it can also be used more generally to refer to the set of representations that composes the mental state of a person at a time. Throughout this essay, 'past experience' is shorthand for the set of representations of a person at some time in the past, and 'sensations, feelings, thoughts' are among the sensory and/or conceptual representations that constitute an 'experience'. As this terminology indicates, the following will offer a representational account of memory and consciousness, and will discuss their relation within this frame.

To begin, Section 1 will develop a distinction between implicit and explicit representation to show how the past figures in all three forms of memory, and uniquely in episodic memory. In procedural and semantic memory, the influence of the past is implicit by which I mean that the past experience is used but not represented in the skill or knowledge. While there must have been past experiences of skateboard practice and McDonald's commercials to inform my abilities, no representation of a past experience is needed to accomplish the present task. Episodic memory, in contrast, depends on representing a past experience as past. Proust explicitly recalls the event of drinking tea at the home of his aunt in Combray.

Characterizing episodic memory as the explicit representation of past experience solves puzzles about the 'feeling of pastness' that accompanies this form of memory: how is 'pastness' represented and why is it consciously represented? In Section 2, I show how these puzzles are resolved by a temporal representation theory of consciousness. On this theory, a conscious state represents the present moment, and in the case of episodic memory, it includes a representation of past experience. The embedded account of the 'feeling of pastness' takes past experience to be part of the explicit content of a conscious state. An episodic memory is a representation of the present that includes a representation of the past.

Since episodic memory exhibits a higher-order representational structure on this account, one might be tempted to explain the coincidence of consciousness and higher-order representation in episodic memory by invoking a higher-order theory of consciousness. This impulse would prove unhelpful, however, as higher-order theory does not explain why both representations of current and past experiences are conscious in episodic memory. Section 3, considers and rejects the higher-order thought theory of consciousness in favor 
of a temporal theory. A representation of past experience as past is the reason episodic memories are higher-order and conscious.

Section 4 concludes by considering the essential role of episodic memory in the formation of a temporally extended self. The demands of a social environment motivate development of an ability to track the mental states of others and oneself over time. By incorporating past experience (and future experience) into the present, episodic memory extends experience in time to form the sense of self. Through a careful examination of the function of temporal representation, we can see why the past is not consciously represented in procedural and semantic memory and the value of consciously representing the past in episodic memory.

\section{The nature of memory}

The three cases of memory above utilize very different sorts of abilities, from bodily, habit-based schemas to highly sophisticated semantic and cognitive skills. What feature do they have in common that makes them memories? An obvious initial suggestion is to point to the role of past experience in the success of present behavior. In Analysis of Mind Bertrand Russell calls this mnemic phenomena, where current action "can only be brought under causal laws by including past occurrences in the history of the organism as part of the causes of the present response" [Russell 1921, 55]. This rough first pass usefully highlights the fundamental relation between memory and learning.

When I learned to ride a skateboard in $6^{\text {th }}$ grade, I refined my sensorimotor coordination over the course of many days and months of practice. Neurobiological patterns of perception-action sequences developed to speed reaction times and expand my repertoire of skills. I learned to adjust to different grades and slopes of terrain, although I never mastered jumps or flips. Already in $6^{\text {th }}$ grade, the development of my skateboarding abilities exemplified procedural memory. From simple stimulus-response conditioning to the intricate dexterity of fine artisans, procedural memory is the most basic and widely utilized form of memory. The deep and enduring physiological basis of procedural memory is dramatically exhibited in cases where an ability is tested after a long period of disuse, such as my recent adventure with a skateboard. Though hardly as proficient as I once was, I retain a general sense of how to ride and could regain my proficiency far more quickly the second time around. Skills like skateboarding count as a form of memory, because past experiences are necessary to the success of present actions.

Semantic memory similarly involves the effect of past experiences on present performance. Though the name suggests language and communication abilities, this type of memory includes the retention of any facts that 
could be expressed by a proposition with a that clause. ${ }^{1}$ In semantic memory, information learned at an earlier time is recalled for current use. For example, my perfect recitation of sandwich ingredients displays a well-established semantic memory for this information. The long period between the time I learned this information and my surprising recitation makes this a particularly dramatic (and somewhat disturbing) example of the effect on present action from past experience.

The standard taxonomy of memory by psychologists classifies procedural memory as 'implicit' or 'non-declarative' because the bearer does not recall specific information. Past training is utilized in present abilities but no information about what is remembered can be identified or 'declared'. Semantic memory is categorized as 'explicit' (or 'declarative') because the bearer is able to state the specific information remembered. Here, I declare, are the ingredients for the Big Mac. However, this way of distinguishing between explicit and implicit memory becomes blurred if we think of linguistic ability as a skill [Millikan 2000, chap. 4]. When I recite Big Mac ingredients, I utilize past training in a way very similar to my use of skateboard training; I simply produce the appropriate words without reference to a past learning event. Likewise, procedural memory need not be entirely skill-based. In skateboarding I occasionally rely on a specific rule like 'lean into a turn' to formalize particularly important or tricky procedures. I might even say this rule aloud to reinforce its effect. One could save the standard explicit/implicit distinction by noting that both procedural and semantic memory may be involved in any given activity, but further complications soon arise to motivate a new distinction between explicit and implicit representation in memory.

Of particular concern for the present topic, the notion of 'explicit' memory is often conflated with 'conscious' memory, which is sometimes also conflated with 'intentionally recalled' memory. ${ }^{2}$ In an early discussion of implicit memory, Daniel Schacter suggests that the explicit/implicit distinction is less ambiguous and misleading than the conscious/non-conscious distinction [Schacter 1987]. As these things often go, Schacter's efforts were in vain and the ambiguity of 'consciousness' continues to infect memory research to the detriment of both concepts of consciousness and of explicit representation. One of the goals of this essay is to sort through some of these ambiguities to delineate useful distinctions between explicit/implicit and conscious/non-conscious.

1. Sven Bernecker takes semantic memory to include any knowledge about the world, concepts, rules, and language and may even be extended to include nonconceptual content [Bernecker 2010]. (See his discussion of [Martin 1992] in chapter 1.) Tyler Burge includes both propositional and nonpropositional content in his description of 'substantive content memory' [Burge 2003].

2. In his review of implicit memory theory, Daniel Schacter identifies 'explicit' with 'conscious' and 'implicit' with 'unconscious' [Schacter 1987]. Larry Jacoby advocates an identification of explicit, conscious and intentional (or controlled) memory [Jacoby 1991]. For a review of the history of episodic memory that notes its connection to consciousness, see [Tulving 2002]. 
As a start, take explicit representation to be an item that has the function of covarying with the item it represents, because this isomorphic relation has been successful to the organism in the past. Implicit representation also varies isomorphically with its represented object, but it does so because this relation facilitates explicit representation in some way. In other words, the distinction between explicit and implicit representation is determined by a difference in functional value. ${ }^{3}$ A spatial example might help illustrate the point. In order to reach for the cup on my desk, my visual system must explicitly represent the distance and angle from hand to cup; the functional value of the distance and angle representations is to get the hand to the cup, because this representation will get me something to drink. Additionally, my visual system must implicitly represent my head and arm position, because these factors are relevant to the successful representation of distance and angle. If as it happens I am hanging upside-down in my office, a different physical movement will be required to bridge the distance between hand and cup than if I am sitting comfortably in my chair. Implicit representations earn their keep by aiding the success of explicit representations, which in turn are reproduced by their contribution to the survival of the organism.

With this distinction in place, the peculiar role of past experience in episodic memory becomes clear. While past experience is represented explicitly in episodic memory, it is represented implicitly in procedural and semantic memory. Consider the similarity in the ways procedural and semantic memory utilize the past. Both forms of memory are purely present-tense orientedskills and information are brought to bear on the current task. Past training is essential to correct execution of a skill or semantic task, but the past experiences themselves are not represented. Typing is a good example of an activity that seamlessly combines procedural and semantic memory. As my fingers find their way to the appropriate keys on the keyboard and the words collect themselves into sentences, the success of the sentences I produce depends on past associations between finger movement and keyboard letter as well as a long education in concepts and their relations. The past is implicitly represented in my language production by virtue of its role in facilitating present action.

Failures best demonstrate the important supporting role of past experience on present explicit representation. On the German keyboard, the positions of the ' $z$ ' and ' $y$ ' are the reverse of the English keyboard. To be successful us-

3. The teleological theory of representation that informs this account follows Millikan [Millikan 1984, 1993, 2004]. I extend Millikan's teleosemantic theory to temporal representation and consciousness [Droege 2009]. See [Dienes \& Perner 1999] and [O'Brien \& Opie 1999] for alternative descriptions of the distinction between explicit and implicit representation. While there are interesting threads of similarity in our descriptions, there are important differences as well. Dienes and Perner, for example, offer a similar distinction but focus exclusively on knowledge. My concern is more broad, including perceptual object tracking, effective social interaction and any number of other functions that might involve explicit and implicit representation. 
ing the German keyboard for typing English,${ }^{4}$ my typing movements need to explicitly represent the correct relation of my finger to the appropriate key. However, as anyone knows who has ever tried to retrain a previously acquired skill, implicit representations of past experience on an English keyboard continually obstruct my ability to explicitly represent the position of the ' $\mathrm{z}$ ' and ' $y$ ' on a German keyboard. Though present skill-based performance does not have the function of varying according to past experience - its function is to vary according to the position of the keys in front of me - the success of the skill depends on my ability to utilize past experiences on the German rather than the English keyboard. When the wrong (i.e., English) keyboard experiences inform my action, then I fail to hit the correct key.

A parallel story about failed semantic memory can be told by substituting past linguistic and conceptual training for past keyboard training. My semantic representations function successfully by varying in accord with the states of affairs represented, and past learning experiences are crucial to this function. Causal theories of knowledge rely on the relation between present belief and past experience to satisfy the justification requirement in the traditional analysis of knowledge as justified true belief. Present beliefs are justified when informed by past learning and fail when they are not appropriately correlated with past experience. For example, I may conflate my Middle East geography lessons and falsely believe that Baghdad is the capital of Syria, and Damascus is the capital of Iraq. ${ }^{5}$ My semantic representations fail to accord with past learning (presuming the original instruction was correct), and so an essential condition for successful representation is not met. Nonetheless, the representation is implicit because its function is to facilitate current representation, not to represent the past experience per se. The current relation between capitals and countries is what I need to represent explicitly, not my experience of learning this information. This is why the appropriate relation to past experience satisfies only the justification requirement for knowledge, not the truth requirement. In terms of knowledge, the functional value of explicit semantic representation can be assessed by its capacity to produce truth and the functional value of implicit semantic representation by its capacity to provide justification.

As important as past experience is to the success of present semantic representation, it is equally important that it remains implicit rather than explicit. If every knowledge state triggered the explicit representation of past learn-

4. Though I don't recommend this as standard practice, I do recommend a visiting lectureship in Germany where typing on German keyboards may be required. Sincere thanks to the Berlin School of Mind and Brain and the DAAD for giving me the opportunity to discover this example.

5. Not all semantic memory errors are explained by failures of implicit representation. I may simply fail to remember anything at all or I may invent a name. However, any invented name necessarily draws on some semantic memory or a combination of them, so there may be no clear line between a simple failure of explicit semantic representation and a failure to draw on the appropriate implicit representations. 
ing experiences, the result would be severely debilitating. The extraordinary memory of Jill Price poignantly illustrates this consequence. For Price, each procedural or semantic memory initiates a cascade of the episodic memories associated with the action or information:

At any given moment, anything at all that someone said to me, or some hurtful or ridiculous thing that I said to someone that I desperately wish I could take back, may pop into my mind and yank me back to that difficult day and exactly how I was feeling about myself. The emotional intensity of my memories, combined with the random nature in which they're always flashing through my mind, has, on and off through the course of my life, nearly driven me mad. [Price 2008, 38], quoted in [Bernecker 2010, 2]

While there is a clear value to implicit representation of past experiences in procedural and semantic memory, what might be the value of explicitly representing the past? A considerable amount of work is required before we answer this question in Section 4. For one thing, we need a better sense of what explicit representation of past experience involves and how it is related to episodic memory. In his original definition, Endel Tulving identified the specific content of what, where and when a particular event (episode) occurred as the marker of episodic memory [Tulving 1972]. As the heyday of behaviorism waned and the interior of the mind became acceptable to the scientific study of psychology again, Tulving added a phenomenological condition: in episodic memory the subject 're-experiences' the past event [Tulving 1983, 2002]. It is this unique phenomenological requirement that sets episodic memory apart and will help clarify the relation between consciousness and explicit representation of past experience.

Consider a non-pathological case where procedural memory generates an episodic memory. As I casually type these words I do not explicitly represent my experiences as a high school and college student when I painstakingly learned this skill. But then, once I begin thinking about my earlier typing experiences, they suddenly come rushing back to me with each stroke. I recall searching for the bumps on the F and J key, and staring intently at the blank chalkboard to force tactile rather than visual navigation of the keyboard. I picture my college dorm room as I slowly peck away at the words of my essay while my roommate chides my clumsy efforts. Though procedural memories represent past experience implicitly by relying on the practice that formed the skill, sensory or cognitive cues may prompt the explicit representation of the past experience on which a skill — or concept or belief, in the case of semantic memory - is based.

In contrast to procedural and semantic memory, episodic memory involves the explicit representation of past experience, because the functional value of the representation is determined by its accord with just that experience. In typing, my skill depends on the appropriate past experience, but the goal is to represent the position of the keys and the concepts in a sentence. In episodic 
memory, the goal is to represent the past experience itself. The next question is: how does memory represent the past as past (Section 2)? Followed by: why is this sort of memory conscious (Section 3)? Finally: what function is fulfilled by an explicit representation of past experience (Section 4)?

\section{How to represent the past}

Early in the $20^{\text {th }}$ century, Bertrand Russell recognized the peculiar role of episodic memory as an explicit representation of the past. Of course, he did not use this contemporary terminology. Here is his distinction between two forms of memory - perception and recollection:

What is called perception differs from sensation by the fact that the sensational ingredients bring up habitual associatesimages and expectations of their usual correlates - all of which are subjectively indistinguishable from the sensation. The FACT of past experience is essential in producing this filling-out of sensation, but not the RECOLLECTION of past experience. [Russell 1921, 107]

In recollection as opposed to perception, a 'memory image' or copy of the past experience accompanies present sensation. As Russell astutely observed, the problem is that the memory image is not logically connected to the past experience that it is supposed to copy. To secure this connection the image must be accompanied by the belief that 'this existed', where 'this' refers to the content of the image, and 'existed' refers to a combined feeling of pastness with a feeling of reality [Russell 1921, 125-126]. Recollection, therefore, is a case of a direct reference to the past experience by means of the memory image. It may seem this must be a case of indirect reference with the memory image as a mediating representation. But for Russell, the memory image is a copy of the past sensation and so one is directly acquainted with the past when experiencing an image directly caused by the past. ${ }^{6}$ The accompanying belief that 'this existed' asserts what the image presents, that one is acquainted with an actual past experience.

Russell's goal in this analysis was to account for memory with a spare ontology composed only of sensations and images, and its virtue is in capturing the sense that one is 're-experiencing' the past events themselves. The Russellian way to read Proust's example transports the narrator back in time as if he were again seeing the town of Combray where he had spent many summer days. But this is implausible. Despite the rich experience of a vivid

6. For Russell, sensations are not representations of external phenomena, they are the metaphysical constituents of both mental and physical objects. Consequently, one can be as directly acquainted with the images that constitute one's past experience as those that, along with sensations, constitute one's present experience. 
memory such as Proust describes, even he admits a more tenuous connection to the past event, noting the fragile quality of memory, its uncertainty and its inventiveness [Proust 1928, 63]. While our beliefs about past and future, reality and fiction do differ, these differences beg explanation rather than offer it. Why are some images accompanied by a belief that 'this existed', and what determines when that belief is appropriately applied? In particular, Russell offers no account of the 'feeling of pastness' essential to episodic memory. Given that memories are a constructive and fallible affair, a full account of memory must show how a feeling of pastness comes to be attached to an image and when that feeling accurately signifies the appropriate causal relation between the past event and the current image. Even in cases where a person has a detailed recollection of specific features of an event, errors of omission, addition or various combinations of features are likely. ${ }^{7}$ The features we remember from an event will be those that resonate in some way with the present situation, either due to a cue like Proust's tea and madeleine cakes or due to the relevance of a past event to current action. Details from the past are selected and combined to serve functions that rarely depend on a precise reproduction of the past event.

Another reason to think episodic memory is not a matter of directly experiencing a past event comes from the phenomenology of episodic memory. Memories don't transport us into the past; they don't even make us feel transported into the past, at least I do not feel transported in this way. ${ }^{8}$ My episodic memories seem rather to bring the past into the present. My spatio-temporal location does not shift so much as multiply, adding the sensations, feelings and thoughts from the past event to those of the present. This feature of inclusion in the present is, I maintain, why episodic memory is the only form of conscious memory. On my view, conscious states are composed of representations of the world ${ }^{9}$ at the present moment, and embedded within a representation of what is present are the sensations, feelings and thoughts that represent the past. So, for example, Proust's memory is the representation of the present moment on a winter's day, which includes sensory representations of the taste of tea and madeleines, and in addition, it includes representations of his past summertime experiences in Combray. Though it may be romantic to think

7. Psychologist Ulrich Neisser compared the remarkably detailed testimony of John Dean, former counsel to President Nixon, to tape recordings of the same events [Neisser 1981]. While Dean accurately recounted the general narrative structure of events, his testimony misattributes details of one event to another and confabulates statements of participants (Discussed in [Martin 2001], see also [Schacter \& Addis 2007], [Dudai \& Carruthers 2005]).

8. Others might feel differently. Phenomenological accounts face a difficult challenge when sincere first-person reports fundamentally differ. For more on this issue, see note 12 .

9. I include both internal and external aspects of the 'world'. Moods, thoughts, and bodily sensations such as pains can be represented in consciousness, as well as trees, friends and sunsets. 
of ourselves as revisiting the past through episodic memory, a more plausible account is that we bring representations of the past into the present.

How might this work? Like Proust, I sit firmly entrenched in the present, with my desk, computer and coffee before me. We can schematize this representational moment in the following way:

$$
\text { \{now, here } \rightarrow<10: 12: 33 \text {, office, desk, computer, coffee }>
$$

The \{\} brackets indicate indexicals, and the $\rightarrow$ arrow maps the indexical function from context to its representational content. $<>$ symbols mark the content so mapped. Since I am relying on my own, perhaps unfamiliar, theory of consciousness, let me expand on this analysis a bit. The items indicated in $<>$ are the representational contents that compose my conscious state. What makes these representations conscious, as opposed to the many other mental representations occurring unconsciously, is that these fulfill the function of a conscious state to represent the present moment. Conscious representations are the best approximation of the world now. ${ }^{10}$

To include a memory in the frame of this conscious representational moment we need to embed a representation of a past experience generated in Proustian fashion from a sip of my coffee. Suddenly, the tiny country house of my graduate school years in Connecticut appears before me, a fire ablaze in the hearth, my copy of Language, Thought and Other Biological Categories lying neglected on my lap; the cat curls cozily on the chair beside me, snowy garden and woods beyond. To capture the temporal complexity of this representation requires a schema that somehow incorporates this past experience into the present. Consider the following:

\{now, here $\} \rightarrow<10: 15: 12$, office, desk, coffee, [past experience] $>$ where [past experience $]=[$ past, there $\} \rightarrow<$ sometime in the mid-1990s, Storrs, fire, book, cat $>$ ]

In this schema, the [] brackets indicate representational content from the past experience as embedded in my representation of the present moment. ${ }^{11}$ The structure is higher-order; a representational state from the past is represented as part of the content of the represented present. ${ }^{12}$ In the next section, I will consider whether this higher-order representational structure casts any

10. For a fully developed argument in favor of this view, see [Droege 2009, 2003].

11. There may be a need to include self-reference so as to identify the memory as mine. It would be fairly easy to add another indexical if one belongs, but I am not convinced that memories are necessarily self-identifying.

12. In the case where one feels transported into the past, the indexical indicator for \{now, here\} would map the representational contents from the past event. Such a representation would not be higher-order, nor would there be a 'feeling of pastness'. Phenomenologically, the experience misrepresents the past event as now. Such a person might know the event is past-as when a lucid dreamer knows she is dreaming - but the experience is represented as present on the direct perception account. 
light on why episodic memories are conscious, though procedural and semantic memories are not.

Before we move on to the relation of episodic memory to consciousness, a potential objection from Mohan Matthen needs to be addressed [Matthen 2010]. Matthen has argued that pastness cannot be part of the content of an episodic memory because episodic content is imagistic. Since an image cannot look as if it is causally descended from a previous experience, temporal content cannot be part of the experience as represented. Instead, Matthen takes pastness to be a cognitive feeling that functions as a way of entertaining the episodic image. The temporal marker serves as an adverbial modification of a propositional attitude - I experience pastly: sitting by the fire, etc.

There are two problems with this analysis that highlight the advantages of an embedded representational account. First, Matthen's account treats the content of episodic memory as indistinguishable from perceptual content, yet denies that the similarity between these forms of content is a matter of the preservation of content from one state to the next. According to Matthen, what is preserved in memory is a trace or engram that is retained subpersonally and then later "entertained" as a memory by means of the episodic operator 'experiences pastly' [Matthen 2010, 11]. The trace functions as a kind of rock in the brain; it sits quietly until called upon to serve as the "categorical basis" for memory construction [Matthen 2010, 7]. But how does the brain manage to distinguish one trace as the basis for my memory of lunch yesterday from another trace that is my memory of my $6^{\text {th }}$ birthday if the difference is not determined by the representational content of these two vehicles? This mysterious meat-to-memory process has the aura of alchemy when severed from a representational theory. It may be that Matthen objects to a particular notion of representational content as a data file that can be stored and accessed without modification at a later date. ${ }^{13}$ If so, he may be amenable to a teleosemantic view of memory where the function of representing the past determines the representational content preserved in memory.

Even if we agree about the representational content of memory, the second problem with Matthen's analysis of pastness as a cognitive feeling is that it describes rather than explains the phenomenon. We can ask the same questions we put to Russell: why are only some images accompanied by the feeling of pastness, and what determines whether this feeling is appropriate or not? Some connection between the feeling of pastness and the fact that the event represented really was an event in one's own past is needed to explain where the feeling of pastness comes from and in what way it is useful.

13. His target is Tyler Burge's description of 'purely preservative memory' [Burge 2003]. It is worth noting that Burge distinguishes this type of memory from 'experiential memory' which he takes to "introduce new subject matter into current thinking" [Burge 2003, 289]. Consequently, it is unclear whether the argument applies to experiential memory. 
Matthen can again offer a functional account of cognitive feeling such that it is designed to entertain images from one's past. But if this is the response, then an embedded representational account is essentially similar and far simpler. On an embedded account, representational relations explain similarities and differences in content between conscious perception and episodic memory, and why 'pastness' is a content attached to the latter, while 'presentness' is a content attached to the former. Starting with 'presentness', we can think of conscious perception as a representation of the present moment, designed to indicate current conditions that enable the creature to plan future action in light of past progress toward its goals [Droege 2003, 2009]. On this view, consciousness represents the present explicitly and the past implicitly when utilizing procedural and semantic memory. Temporal representation is entirely present-tense oriented. Past and future are not conceived abstractly as temporal moments independent of present action; they are distinguished from the present in purely relational terms. In contrast, we can think of episodic memory as an explicit representation of the past. Its functional value is rooted in its representation of a past experience itself, that is, a representation of the past as past. By interpreting the 'feeling of pastness' in terms of explicit temporal content, we can explain why memories are supposed to be similar to the experiences they reproduce - their function is to vary in accord with those experiences - and also why they may fail to fulfill that function and still count as 'memories'.

Given the unspecific and reconstructive character of memory, the past experience represented may be composed of several events from an indeterminate span of time. In regard to the memory described above, there may not have been a single event where fire, cat, chair, and book were combined. Certainly I experienced all of these elements in various combinations, but I could not say for certain that there is a single episode of what, where, when that the memory references. Nor need there have been. Though episodic memory got its name as a type of memory for determinate 'episodes', there is good reason to think that the function of representing past events, even the explicit representation of past events, is a more flexible operation than the traditional description suggests. ${ }^{14}$

14. Though 'memory' is often taken to be a success word, contemporary research suggests that such a characterization would restrict the category of memory quite severely, perhaps to nothing. Moreover, from the first-person perspective we are unable to distinguish memories that are perfectly accurate about the past from those that are false or confabulated in some way. Consequently, all our 'memories' would be suspect, not merely as potentially fallible, but as potentially something other than a memory. The truth-requirement for 'memory' is not worth these costs, in my view. 


\section{Consciousness and representation of the past}

The previous section proposed a theory of the pastness in episodic memory in terms of an explicit representation of past experience embedded in a representation of the present. The next question is why episodic memories are the only sort of memory that is conscious. It is certainly possible to explicitly represent a past experience without consciously re-experiencing its features. While an embedded account can explain the attribution of pastness to the representation of past experience, something more is needed to explain why the past should be represented consciously. In procedural and semantic memory, the past experiences utilized in present action remain unconscious. I do not consciously re-experience my past when skateboarding, reciting hamburger ingredients or typing essays. Only in episodic memory do I consciously reexperience the past.

Not coincidentally, a higher-order structure is also unique to episodic memory. As argued earlier, I do not represent past experiences in my exercise of a skill, even though past experiences are necessary to have formed the skill. Habits of action are encoded in the nervous system precisely in order to circumvent deliberative mental processes that slow reaction time. Explicit representation of past experiences and reasoning about those representations would add an unreasonable computational burden to an otherwise smoothly functional machine. For similar reasons, my spontaneous production of the words to the McDonald's jingle need not be accompanied by a representation of the past experience when these words were learned. For procedural and semantic forms of memory, first-order representation of the appropriate information is sufficient. Of course, some semantic memories are clearly higherorder, such the thought that I have been thinking about memory all week. I will consider these cases in Section 4 in relation to the function of episodic memory and other higher-order states. My point here is that these forms of memory are not necessarily, nor I would say, usually higher-order. Episodic memory, by contrast, necessarily has a higher-order structure on my account; it is an embedded representation of past experience within the current representational state.

That is, conscious episodic memory is necessarily higher-order. One might wonder whether it is possible for episodic memories to be unconscious. Prior to retrieval, the material for constructing my $6^{\text {th }}$ birthday memory presumably exists in the form of unconscious representations, the content of which is preserved from the time of my birthday experiences, or so I argued in Section 2. If we consider this representational content an unconscious episodic memory, it would not be higher-order; it would simply be the set of sensations, feelings and thoughts that represent my $6^{\text {th }}$ birthday. ${ }^{15}$ When conscious, my represen-

15. Even so, what makes this form of memory unique is the 'conscious reexperiencing of the past' noted in Tulving's definition [Tulving 1983, 2002]. So, 
tation of the present represents these representations, and they are therefore higher-order.

This coincidence of consciousness and higher-order structure as unique to episodic memory might lead one to a higher-order representational theory of consciousness in a search for explanation. According to higher-order theory, a state is conscious when there is an appropriate sort of higher-order representation of it. Higher-order theorists differ on what sort of representation is the appropriate sort-thought or sensation, intrinsic or relational, assertoric or dispositional. For the purposes of argument, I will consider the clearly-structured higher-order thought theory, defended by David Rosenthal [Rosenthal 1993, 1997, 2004], to show that the coincidence between metarepresentational states and consciousness in episodic memory does not lend support to higher-order theories.

According to Rosenthal, a mental state is conscious when there is a higherorder thought (HOT) about it [Rosenthal 1997, 737]. Following this account, a particular type of HOT could mark representations as past in a way similar to the embedded account given above. As I sit here at my desk reminiscing about my graduate student days, I may have a thought with the content:

I remember that I sat by the fire with a book on my lap and the cat nearby.

Because the past experience forms the content of the higher-order thought, this mental state is conscious. The type of higher-order thought - rememberingincludes the temporal content that the experience occurred at some time in the past. ${ }^{16}$ This simple explanation in addition to the fact that episodic memories are the only form of memory that is necessarily conscious and necessarily higher-order seems to be good support for the higher-order theory of consciousness. When memories are unconscious - either because they are procedural or semantic, or because they are dormant episodic memories - they lack higher-order structure. If a state is only conscious when there is a higher-order thought about it, the coincidence of episodic memory, higher-order structure and consciousness is just what one would expect.

The problem with this explanation can again be found in the phenomenology of episodic memory. As mentioned earlier, no memory transports us to a past event; we always continue to experience our current environment while simultaneously experiencing remembered sensations and thoughts. So,

where not otherwise noted, 'episodic memory' refers to conscious representations of past experience. Thanks to David Pereplyotchik and David Rosenthal for pressing me to clarify this point.

16. A higher-order thought theorist could also adopt Matthen's adverbial approach and analyze the type of HOT as 'thinking pastly'. Matthen would likely object to the metacognitive account, however, as failing to explain the feeling of pastness that accompanies the representation of the event [Matthen 2010, 10]. For his part, Rosenthal would probably also resist the inner sensory cast of Matthen's 'cognitive feelings'. 
in addition to the clearly higher-order structure of episodic memory, we simultaneously have first-order conscious states about things we are experiencing right here and now. These first-order conscious states can be easily accounted for by higher-order thought theory as sensory states of which we are conscious by virtue of higher-order thoughts. But now we are reminded of the fact that the higher-order thoughts by virtue of which mental states are conscious are not themselves conscious. For a HOT to be conscious requires a yet higher-order thought (HOT2) to take that HOT as its content [Rosenthal 1997, 745]. Episodic memories are higher-order in the sense that past mental states are represented by current mental states, both of which are conscious. The higher-order structure of episodic memories occurs within consciousness, so the higher-order structure cannot without circularity explain the fact that episodic memories are conscious. Consequently, a yet higher-order thought would be needed to explain conscious episodic memory, removing the illusion that the coincidence between the higher-order structure of episodic memory and its uniqueness as the only conscious form of memory is a reason to adopt a higher-order account of consciousness. Nor does the theory explain why the higher-order structure of episodic memory is conscious. Consistent with HOT theory is the possibility that episodic memory could just as well have remained unconscious, like procedural and semantic memory, informing about the past without explicitly representing the past. Or the present moment might have disappeared from conscious content entirely in the way memory is depicted in films - the screen blurs and the past replaces the present as the content of the image. There are certainly explanations consistent with the higherorder thought theory, but they are not supplied by the theory. Therefore, the coincidence between the higher-order structure of episodic memory and its consciousness does not in itself support the higher-order thought theory of consciousness. ${ }^{17}$

In contrast, the fact that episodic memory is included in a representation of the present moment as an explicit representation of a past experience explains both its higher-order structure and its consciousness on a temporal representation theory. We explicitly represent both the present moment and the past when we have a conscious episodic memory. Conscious states represent the present moment, which, as just noted, includes an explicit representation of the past. Because this representation of the past is included in the represen-

17. Other forms of higher-order theory do not fare better, which is perhaps why memory appears rarely, if ever, in arguments for higher-order theory. The exception is Rocco Gennaro, who uses episodic memory as an argument for his version of higher-order thought theory [Gennaro 1992, 1996]. However, the argument relies on the conflation of episodic memory with short-term or working memory. While consciousness does indeed depend on a temporally extended or 'specious' present, there is no reason to believe that the specious present depends on an explicit concept of the past which is required for episodic memory. Therefore, the inference from the higher-order structure of episodic memory to consciousness fails in this argument as well. 
tational content of the present moment, it is necessarily conscious and the structure of the episodic memory is higher-order.

Thus, an explanation of several facets of episodic memory falls out of a theory of consciousness described in terms of temporal representation. An analysis of memory as a representation of the past links procedural, semantic and episodic memory together, while the distinction between implicit and explicit representation of the past accounts for the 'feeling of pastness' unique to episodic memory. Given the capacity of implicit forms of memory to effectively inform many complex behaviors, the next question is what function explicit representation of the past in episodic memory might serve in human experience.

\section{Why episodic memory might be useful}

Speculation on the functional value of a mental attribute such as episodic memory is properly the purview of psychology, and I will draw on some of this work in the following. In addition, armchair philosophical analysis highlights ways in which episodic memory forms the basis for a sense of self over time. As we will see, empirical and philosophical discussions converge to tell a story about the essential role of episodic memory in the emergence of a temporally extended self. Three strands of research connect the need to anticipate the actions of others in a social environment as an evolutionary incentive for a theory of mind, the representation of one's own experience over time, and the development of a unified self. Let me begin with a just-so story from Nicholas Humphrey about the origins of the ability to track the mental states of others and oneself [Humphrey 1983].

In the beginning there were creatures capable of sensation and intelligent action, but without the ability to monitor their own states. Over the course of time some of these creatures discovered that forming social groups could be useful in defending themselves against predators, finding food, and generally having fun. One problem with being social, though, is that other creatures can be unpredictable. Suddenly one guy gets angry or another starts acting silly, and it is hard to understand why. To try to reduce some of this uncertainty, some of the creatures started to keep track of how different members of the group responded to different events in order to better anticipate what causes would bring on what sort of behavior from whom. After awhile these clever creatures - which Humphrey calls 'nature's psychologists' - realized they could apply these same tracking abilities to their own reactions in order to understand themselves better.

Stories such as this one cannot be definitively proven, but the basic connection between social interaction and mind-reading skills is fairly uncontroversial. Disagreements arise over how social interaction drives the development of these skills - through simulation, a theory theory or a theory of rationality 
[Goldman 2006]. More controversial may be the claim that the capacity for reading other minds is the source of our own self-conscious reflection. One might be inclined to think, for example, that self-consciousness is more basic, and mind-reading is matter of inferring to others on the basis of one's own case. Though this view problematically makes self-consciousness inexplicable, it is nonetheless compatible with the point I want to make about episodic memory. Even if one is conscious of one's own states prior to the ability to interpret the mental states of others, there is no reason to keep track of mental states without the driver of social pressure. In the context of a group, a creature needs to be aware of and appropriately manage her own mental states, as well as the mental states of others to whatever extent she can. The desert island dweller has no use for self-reflection, because there is no value in tracking her own states. Without an Other to react well or badly as a consequence of a happy smile or angry outburst, the mental states that generate these behaviors can occur unregulated. One merely needs to act on one's fears and desires appropriately; there is no need to represent them as well. In a social environment, on the other hand, self-monitoring becomes crucial, either initiating the development of self-conscious reflection or activating an innate capacity.

Episodic memory is a critical component of self-conscious reflection because it connects past, present and future experiences. Past experiences are incorporated into a representation of the present, according to the embedded account of episodic memory proposed above. A single conscious state includes representations of both present and past events, generating a link between experiences represented as occurring at distinct times. Episodic memory brings the past forward into direct contact with the present. Make no mistake, this is a representational theory, not an acquaintance theory. Nonetheless, the intuitive appeal of acquaintance can be accounted for by the fact that past and present experience are included in the same representational state.

Representations of future experiences may also be formed on the basis of episodic memories, according to recent research. Studies of amnesic patients show that the ability to imagine future events is severely restricted relative to control subjects, suggesting the capacity to re-experience the past is linked to the capacity for envisioning the future [Maguire, Vargha-Khadem \& Hassabis 2010], [Kwan, Carson, Addis et al. 2010]. Developmental evidence indicates that 'episodic future thinking' emerges with episodic memory between ages 3 and 4 [Atance \& O'Neill 2005], and neurophysiological evidence shows that similar neural systems are engaged in imagining both future and past [Addis, Pan, Vu et al. 2009], [Okuda, Fujii, Ohtake et al. 2003]. Daniel Schacter and Donna Addis have suggested that the functional value of episodic memory may be attributable more to the imagination of future events than the accurate representation of the past [Schacter \& Addis 2007]. The dual use of memory contents explains the fallible, reconstructive nature of episodic memory. Rather than function as a video recorder of events, memory representations function as components for reconstruction of past events as well as flexible combination 
and configuration of hypothetical scenarios. ${ }^{18}$ If the only function of episodic memory were to acquaint us with the past, one would expect a much more efficient system than one influenced by linguistic cues, context and motivational factors. More plausible is a system designed to project our experiences in both directions in time. Episodic memories provide the connection to our experiences in the past as well as the material for anticipating the experiences we hope to have in the future.

This bi-directional temporal projection of experiences from past to present to future provides the ground for a spatiotemporally continuous self as the bearer of a relatively consistent set of experiences over time. John Locke classically utilized the coincidence of past and present experience in memory as a criterion for personal identity:

[...] as far as this consciousness can be extended backwards to any past action or thought, so far reaches the identity of that person; it is the same self now it was then; and it is by the same self with the present one that now reflects on it, that that action was done. [Locke 1689, Book II, chap. 27, §9]

Because my consciousness now includes a consciousness of the past, the two experiences can be attributed to the same person. This is not to say that Locke offers the best theory of personal identity; it is simply a recognition of the compelling power of episodic memory to establish a sense of ourselves over time. The immediacy of conscious recollection supplies what William James called the 'warmth' that constitutes the feeling of self. ${ }^{19}$ We need not decide whether episodic memory grounds personal identity or assumes it to note the integral relation between them. Episodic memory is certainly an essential tool for keeping track of oneself as the same self over time.

A spatiotemporally continuous, or temporally extended self, is completely devastated by the loss of episodic memory and future imagining despite the retention of semantic memories. Oliver Sacks tells the story of a man with severe retrograde and anterograde amnesia as a result of Korsakoff's syndrome [Sacks 1970]. Because Mr. Thompson has no episodic memories to form his life, he is driven to confabulate a narrative in a desperate attempt to make sense of an otherwise meaningless series of events. Sacks describes the case as a loss of 'inner drama':

To be ourselves we must have ourselves - possess, if need be repossess, our life-stories. We must 'recollect' ourselves, recollect the inner drama, the narrative, of ourselves. A man needs such a narrative, a continuous inner narrative to maintain his identity, his self. [Sacks 1970, 111]

18. The flexible, reconstructive process by which episodic memory consciously represents the past is further reason to identify its conscious instantiation as definitive of this form of memory. See note 15 .

19. "Remembrance is like direct feeling; its object is suffused with a warmth and intimacy to which no object of mere conception ever attains" [James 1892, 158]. 
Episodic memory supplies the experiential thread that strings the pearls of a life into the strand of a self. Without the conscious experience of one's past and future, the information about oneself forms at best an inferential, thirdperson self. One knows oneself in the same way one knows others, as a set of stories that narrate a character. The 'warmth' that James felt as essential to the self is missing without the conscious representation of time provided by episodic memory.

Semantic memories, even higher-order ones, cannot provide this experiential link. As noted earlier, many higher-order representations of past experiences do not involve re-experiencing the past. I might think to myself, 'My goodness, I have been thinking a lot about memory this week'. My thought represents my past thoughts about memory. Since my past thoughts about memory are explicitly represented, it seems to follow on my account that they are necessarily consciously represented. But clearly they need not be. Note that in such cases I am not explicitly representing the past experience, I am explicitly representing the fact that a past experience occurred. The difference is similar to my episodic memory of walking up the 704 steps of the Eiffel Tower to my semantic memory of the fact that there are 704 steps from the ground to the $2^{\text {nd }}$ floor of the Eiffel Tower. Explicit representation of experience rather than fact is constitutive of episodic memory and the aspect of memory necessary for a sense of oneself as extended in time.

\section{Conclusion}

These considerations about the role of episodic memory in grounding a temporally extended self explain why episodic memory is often the only form of memory philosophers take to be of any interest. Nonetheless, a comparison of episodic memory with procedural and semantic memory highlights the importance of past experience in all three forms of memory. Episodic memory is unique in being the only form of memory that explicitly represents the past and the only form of memory that is conscious. A temporal representation theory of consciousness explains the coincidence of these two features in terms of an embedded representation of past experience within a representation of the present moment. When Proust remembers things past, he incorporates them into his representation of the present to form a nest of temporal experiences which are the basis for a story of the self.

\section{Bibliography}

Addis, D. R., Pan, L., Vu, M., Laiser, N. \& Schacter, D.L.

2009 Constructive episodic simulation of the future and the past:

Distinct subsystems of a core brain network mediate imagining and remembering, Neuropsychologia, 47, 2222-2238. 
Atance, C. M. \& O’Neill, D. K.

2005 The emergence of episodic future thinking in humans, Learning and Motivation, 36, 126-144.

BERNECKER, S.

2010 Memory: A Philosophical Study, Oxford: Oxford University Press.

Burge, T.

2003 Memory and persons, The Philosophical Review, 112(3), 289-337.

Dienes, Z. \& Perner, J.

1999 A theory of implicit and explicit knowledge, Behavioral and Brain Sciences, 22, 735-808.

Droege, P.

2003 Caging the Beast: A Theory of Sensory Consciousness, Amsterdam: John Benjamins Publishing.

2009 Now or never: How consciousness represents time, Consciousness and Cognition, 18, 78-90.

Dudai, Y. \& Carruthers, M.

2005 The Janus face of mnemosyne, Nature, 434, 567.

Gennaro, R. J.

1992 Consciousness, self-consciousness and episodic memory, Philosophical Psychology, 5(4), 333-347.

1996 Consciousness and Self-Consciousness: A Defense of the HigherOrder Thought Theory of Consciousness, Amsterdam: John Benjamins Publishing.

Goldman, A.

2006 Simulating Minds: The Philosophy, Psychology and Neuroscience of Mindreading, Oxford: Oxford University Press.

Humphrey, N.

1983 Consciousness Regained, Oxford: Oxford University Press.

JACOBY, L. L.

1991 A process dissociation framework: Separating automatic from intentional uses of memory, Journal of Memory and Language, 30(5), $513-541$.

JAMES, W.

1892 Psychology, New York: Henry Holt \& Co.

Kwan, D., Carson, N., Addis, D. R. \& \& Rosenbaum, R. S.

2010 Deficits in past remembering extend to future imagining in a case of developmental amnesia, Neuropsychologia, 48, 3179-3186. 
LOCKE, J.

1689 An Essay Concerning Human Understanding, edited by Peter Nidditch, Oxford: Clarenden Press, 1975.

Maguire, E. A., Vargha-Khadem, F. \& Hassabis, D.,

2010 Imagining fictitious and future experiences: Evidence from developmental amnesia, Neuropsychologia, 48, 3187-3192.

Martin, M. G. F.

1992 Perception, concepts and memory, Philosophical Review, 101(4), 745-763.

2001 Out of the past: Episodic recall as retained acquaintance, in Time and Memory: Issues in Philosophy and Psychology, edited by HoERL, C. \& McCormack, T., Oxford: Oxford University Press, 257-284.

Matthen, M.

2010 Is memory preservation?, Philosophical Studies, 148, 3-14.

Millikan, R. G.

1984 Language, Thought, and Other Biological Categories, Cambridge, MA: MIT Press.

1993 White Queen Psychology and Other Essays for Alice, Cambridge, MA: MIT Press.

2000 On Clear and Confused Ideas, Cambridge: Cambridge University Press.

2004 Varieties of Meaning, Cambridge, MA: MIT Press.

NEISSER, U.

1981 John Dean's memory: A case study, Cognition, 9, 1-22.

O'Brien, G. \& Opie, J.

1999 A connectionist theory of phenomenal experience, Behavioral and Brain Sciences, 22, 127-196.

Okuda, J., Fujin, T., Ohtake, H., Tsukiura, T., Tanji, K., Suzuki, K., Kawashima, R., Fukuda, H., Iтоh, M. \& Yamadori, A.

2003 Thinking of the future and past: The roles of the frontal pole and the medial temporal lobes, NeuroImage, 19, 1369-1380.

PRICE, J.

2008 The Woman Who Can't Forget: The Extraordinary Story of Living with the Most Remarkable Memory Known to Science, New York: Free Press, B. Davis (Contributor).

Proust, M.

1928 Swann's Way, New York: Random House, translated by C.K. S. Moncrieff.

Rosenthal, D. M.

1993 State consciousness and transitive consciousness, Consciousness and Cognition, 2, 355-363. 
1997 A theory of consciousness, in The Nature of Consciousness: Philosophical Debates, edited by Block, N., Flanagan, O. \& Güzuldere, G., Cambridge, MA: MIT Press, 729-754.

2004 Varieties of higher order theory, in Higher Order Theories of Consciousness, edited by Gennaro, R. J., Amsterdam: John Benjamins Publishing, 17-44.

Russell, B.

1921 The Analysis of Mind, Rockville, MD: Arc Manor, 2008.

SACKS, O.

1970 The Man Who Mistook His Wife for a Hat and Other Clinical Tales, New York: Harper Perennial.

Schacter, D. L.

1987 Implicit memory: History and current status, Journal of Experimental Psychology: Learning, Memory, and Cognition, 13(3), 501-518.

Schacter, D. L. \& Addis, D. R.

2007 The ghosts of past and future, Nature, 445(4), 27.

Tulving, E.

1972 Episodic and semantic memory, in Organization of Memory, edited by Tulving, E. \& Donaldson, W., New York: Plenum, 381-403.

1983 Elements of Episodic Memory, New York: Oxford University Press.

2002 Episodic memory: From mind to brain, Annual Review of Psychology, 53, 1-25. 